\title{
Dynamic Analysis of a Rotor-Bearing-SFD System with the Bearing Inner Race Defect
}

\author{
Junhong Zhang, ${ }^{1,2}$ Xin Lu, ${ }^{1}$ Jiewei Lin, ${ }^{1}$ Liang Ma, ${ }^{1,2}$ and Jun Wang ${ }^{2}$ \\ ${ }^{1}$ State Key Laboratory of Engines, Tianjin University, Tianjin 300072, China \\ ${ }^{2}$ Department of Mechanical Engineering, Tianjin University Renai College, Tianjin 301636, China \\ Correspondence should be addressed to Jiewei Lin; linjiewei@tju.edu.cn and Liang Ma; mliang@tju.edu.cn
}

Received 26 September 2016; Revised 22 November 2016; Accepted 4 December 2016; Published 4 January 2017

Academic Editor: Aly Mousaad Aly

Copyright (c) 2017 Junhong Zhang et al. This is an open access article distributed under the Creative Commons Attribution License, which permits unrestricted use, distribution, and reproduction in any medium, provided the original work is properly cited.

\begin{abstract}
In this paper, the dynamic behavior of a rotor-bearing-SFD system with the inner race defect of bearing is investigated. The contact force between the rolling element and the race is calculated in Hertzian contact and elastohydrodynamic lubrication condition. The supporting force of the SFD is simulated by integrating the pressure distribution derived from Reynolds's equation. The equations of motion of the rotor-bearing-SFD system are derived and solved using the fourth-order Runge-Kutta method. The dynamic behavior and the fault characteristics are analyzed with two configurations of the SFD: (1) mounted on the unfaulted bearing and (2) mounted on the faulty bearing. According to the analysis of time-frequency diagram, waterfall plot, and spectral diagram, the results show that the characteristics of inner race defects on bearing frequencies are related to the characteristic multiple frequency of the inner race defect and the fundamental frequency. The speed and defect width have different influence on the distribution and amplitude of frequency. The SFD can enhance the system stability under the bearing fault but the enhancement decreases with the increasing speed. Meanwhile, the beneficial effect of the SFD varies according to the mounted position in the rotor system.
\end{abstract}

\section{Introduction}

Bearings are most widely used in rotating machinery as one of the most critical components. However, for the complex running condition of rotating machinery, bearings easily fail. According to research, over $40 \%$ failures are due to bearing defects among failures of motors [1]. Bearing faults may cause unstable vibration of rotor system which leads to serious economic and increase the downtime $[2,3]$. Therefore, it is essential to understand the dynamic and intrinsic transient characteristics of vibration caused by bearing faults.

Bearing faults can be divided into distributed defects and localized defects $[4,5]$. The localized defects, also called single-points defects, include the cracks, pits on the surface of the inner race, outer race, and ball race. The distributed defects include surface roughness, waviness, misalignment races, and off-size rolling elements. In order to study the dynamic characteristics of ball bearing, Kankar et al. [6] developed a model of localized defects on a ball bearing and employed the Fast Fourier Transformation (FFT) and the
Poincare maps to analyze the defects of bearing components. Arslan and Aktürk [7] developed a shaft-bearing model and analyzed the characteristics of bearing defects in frequency and time domains; the frequency characteristics of fault were studied. Patil et al. [8] used the time domain and the power spectrum to study the frequency and acceleration of vibration components of ball bearings and discussed the effects of the defects size and locations.

According to the recent research, the vibration signals are nonstationary and time-varying with the effect of speed changing and the nonlinear characteristics of the rotor system caused by faults. To well extract the transient characteristics from signal data, many signal denoising methods have been developed [9], such as time-domain method, band-pass filtering, frequency-domain threshold, empirical mode decomposition (EMD), wavelet transform (WT), time-frequency analysis (TFA), manifold learning, and matching pursuit. However, there are still some issues that remained to be studied among these denoising methods. In these methods, time-frequency analysis can reflect the change of signal 
characteristics with time and is widely used in faults diagnosis [10]. Ding and He [9] proposed a novel transient signal reconstruction method for bearing fault features extraction and find this method is effective to verify faults characteristics of bearing fault. Liu et al. [11] used a novel fault detection method to study the impact time-frequency dictionary and faulty features of roller bearing defects.

In order to reduce the nonlinear vibration, rotors are often supported by ball bearings with squeeze film dampers (SFD) in many applications [12]. SFD can be designed through introducing a centralized spring and filling the clearance with lubrication oil. In a SFD mounted rotor-bearing system, the bearing can be held in its position statically by the supporting fluid pressure. Meanwhile, the critical speed of the rotor system as well as the stability is able to be controlled by adjusting the SFD parameters. Many scholars focused on the dynamic characteristics of the rotor system affected by SFD [13-15]. Previous work on SFD on a two-disk rotor system with misalignment and the effects of SFD was discussed [16].

However, although various available models represent the dynamics characteristics of rolling element bearings, there is no universal and detailed platform for the whole system [17]. There also need the intensive study of the bearing fault laws about the faults parameters to understand the nature of the fault and the occurrence and development of the fault, so as to timely and accurate to all kinds of anomalies or failure of the emergence and development of the trend to make judgments.

On the basis of previous work [16], this paper developed a model of bearing which considered both Hertz contact and elastohydrodynamic lubrication. This model was focused on studying the fault characteristics of the rotor system caused by inner race defects. The waterfall map, time-frequency map, and spectral diagram were introduced to analyze the dynamic and signal characteristics of inner race defects, studying the law of the frequency characteristics changing with defect parameters. In the end, the effects of SFD to the dynamic characteristics of faults rotor system were discussed.

\section{Model of the Rotor-Bearing-SFD System}

2.1. SFD Model. The schematic of the SFD used in this paper is shown in Figure 1. The instantaneous pressure distribution $p_{s}$ can be calculated using the Reynolds equations [18]:

$$
\frac{1}{R_{s}{ }^{2}} \frac{\partial}{\partial \theta}\left(h_{s}^{3} \frac{\partial p_{s}}{\partial \theta}\right)+h_{s}^{3} \frac{\partial^{2} p_{s}}{\partial x^{2}}=-12 \mu_{s} \Omega \frac{\partial h_{s}}{\partial \theta}+12 \mu_{s} \frac{\partial h_{s}}{\partial t} .
$$

In order to solve the Reynolds equation, the Sommerfeld transformation was introduced [19]; after integrating twice $p_{s}$ can be written as

$$
\begin{aligned}
p_{s}= & \frac{6 \mu_{s}\left(\varepsilon_{s} \Omega \sin \theta+\dot{\varepsilon}_{s} \cos \theta\right)\left(x^{2}-l_{s}^{2} / 4\right)}{c_{s}^{2}\left(1+\varepsilon_{s} \cos \theta\right)^{3}} \\
& +\left(p_{s, 2}-p_{s, 1}\right) \frac{x}{l_{s}}+\frac{1}{2}\left(p_{s, 2}+p_{s, 1}\right),
\end{aligned}
$$

where $h_{\mathrm{s}}=c_{\mathrm{s}}\left(1+\varepsilon_{\mathrm{s}} \cos \theta\right)$, $\mu_{\mathrm{s}}$ is the oil viscosity, $\Omega$ is the precession angular velocity of the journal, $c_{s}$ is the radial

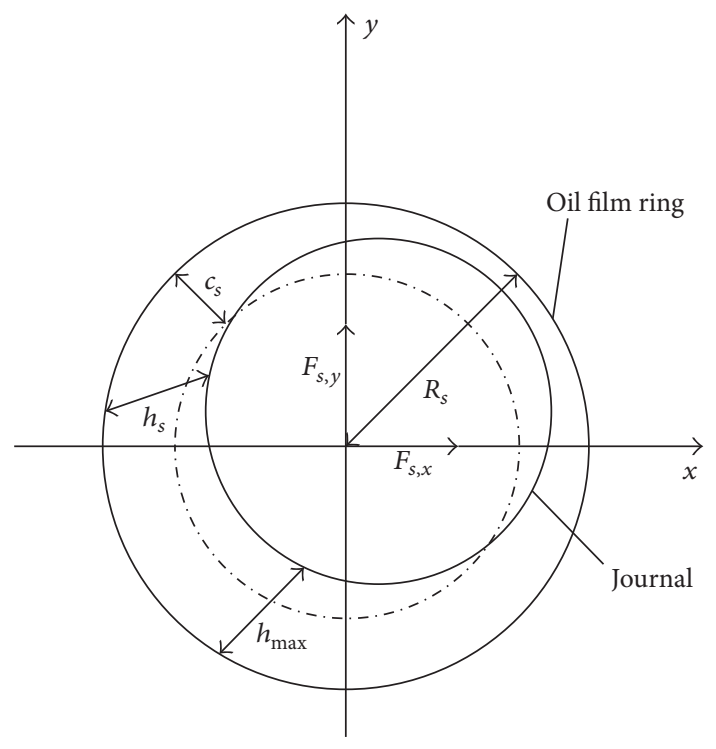

FIGURE 1: Model of the SFD.

clearance of the $\mathrm{SFD}$, and $\varepsilon_{s}$ is the eccentric ratio of the bearing and given as $\varepsilon_{s}=\sqrt{x^{2}+y^{2}} / c_{s}, p_{s, 1}$ and $p_{s, 2}$ are the SFD boundary pressures, and $l_{s}$ is the bearing width.

According to the Reynolds boundary condition, $p_{s, 1}$ and $p_{s, 2}$ are assumed equal to 0 ; the supporting force of the oil film can be obtained as [19]

$$
\begin{aligned}
& F_{s, y} \\
& =-\frac{\mu_{s} R_{s} l_{s}^{3}}{c_{s}^{2} \sqrt{y^{2}+x^{2}}}\left[y\left(\dot{\varepsilon}_{s} I_{1}+\varepsilon_{s} \Omega I_{2}\right)-x\left(\dot{\varepsilon}_{s} I_{2}+\varepsilon_{s} \Omega I_{3}\right)\right], \\
& F_{s, x} \\
& =-\frac{\mu_{s} R_{s} l_{s}^{3}}{c_{s}^{2} \sqrt{y^{2}+x^{2}}}\left[x\left(\dot{\varepsilon}_{s} I_{1}+\varepsilon_{s} \Omega I_{2}\right)+y\left(\dot{\varepsilon}_{s} I_{2}+\varepsilon_{s} \Omega I_{3}\right)\right],
\end{aligned}
$$

where $R_{s}$ is radius of SFD, $I_{1}, I_{2}$, and $I_{3}$ are classic Sommerfeld integral equations; they can be written as

$$
\begin{aligned}
& I_{1}=\int_{\theta_{1}}^{\theta_{1}+\pi} \frac{\cos ^{2} \theta}{\left(1+\varepsilon_{s} \cos \theta\right)^{3}} d \theta, \\
& I_{2}=\int_{\theta_{1}}^{\theta_{1}+\pi} \frac{\sin \theta \cos \theta}{\left(1+\varepsilon_{s} \cos \theta\right)^{3}} d \theta, \\
& I_{3}=\int_{\theta_{1}}^{\theta_{1}+\pi} \frac{\sin ^{2} \theta}{\left(1+\varepsilon_{s} \cos \theta\right)^{3}} d \theta .
\end{aligned}
$$

\subsection{Ball Bearing Model with Faults}

2.2.1. Ball Bearing Model. The sketch of the ball bearing is shown in Figure 2. For the bearing model ignoring the effect of the lubrication oil, the load distribution of the bearing can be determined based on the Hertzian contact 


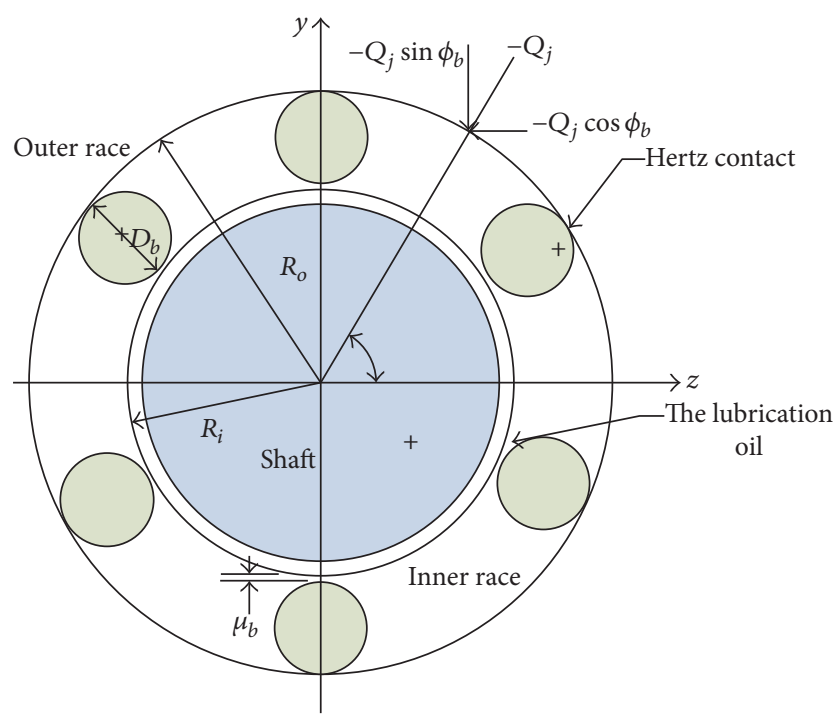

FIgURE 2: Schematic diagram of the ball bearing.

theory $[20,21]$. Due to the working condition of the rotor system, the centrifugal forces of the rolling elements should be considered. The model of ball bearing can be developed by following assumptions:

(1) The outer rings are connected rigidly to the support and inner rings are fixed rigidly to the shaft.

(2) The inner race, ball, and outer race move in the plane of bearing only.

(3) The temperature of bearing is stable when the bearing is in operation.

According to Harris' work [22], the contact stiffness of the ball bearing can be calculated as follows:

$$
\begin{aligned}
k_{b, j}^{H} & =\frac{\partial Q_{b, j}^{i}}{\partial \delta_{b, j}}=\frac{3}{2} Q_{b, j}^{i}{ }^{1 / 3}\left[k_{c, j}^{i}-2 / 3\right. \\
& +k_{c, j}^{o-2 / 3}\left(1+\frac{F_{b, c}}{Q_{b, j}^{i}}\right)^{2 / 3} \\
& \left.-k_{c, j}^{o-2 / 3}\left(1+\frac{F_{b, c}}{Q_{b, j}^{i}}\right)^{-1 / 3} Q_{b, j}^{i}-1\right]^{-1},
\end{aligned}
$$

where $Q_{b}$ is the load of ball, $k_{c}$ is the contact deformation coefficient of the ball, and $F_{b, c}$ is the centrifugal force of the ball. The subscript " $j$ " refers to the ball number, and the superscripts " $i$ " and " $o$ " refer to the inner and outer races, respectively.

Regarding the point contact, the oil film thickness equation proposed by Sarangi et al. [21] is appropriate for the ball bearing:

$$
H_{b}=2.69 U^{0.67} G^{0.53} W^{-0.067}\left[1-0.61 \exp \left(-0.73 e_{b}\right)\right] \text {, }
$$

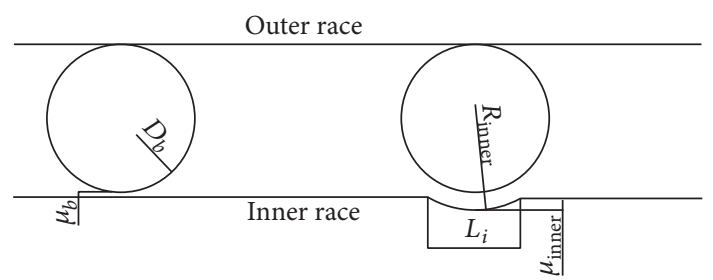

Figure 3: The Inner race defect of the ball.

where $U=\mu_{b} u / 2 E^{\prime} R_{b}$ is a nondimensional velocity, $G=\alpha E^{\prime}$ is a nondimensional material parameter, $W=Q_{b} / E^{\prime} R_{b}^{2}$ is a nondimensional load parameter, $e_{b}$ is the ellipticity of the rolling element, $\mu_{b}$ is the dynamic viscosity, $u$ is the linear velocity, $E^{\prime}=E /\left(1-v^{2}\right)$ is the equivalent Young's modulus, $v$ is the Poisson's ratio, and $\alpha$ is the pressure-viscosity coefficient.

Then the oil film stiffness between the rolling element and the inner race can be calculated as

$$
\begin{aligned}
& k_{E H L}^{i}=\frac{\partial Q_{j}}{\partial H_{b}^{i}}=\left(\frac{\partial H_{b}^{i}}{\partial Q_{j}}\right)^{-1}=-\frac{1}{0.18023} \\
& \cdot \bar{U}^{-0.67} \bar{G}^{-0.53} Q_{j}{ }^{1.067} E^{\prime-0.067} R_{b}^{i-1.134}(1 \\
& \left.-0.61 e^{-0.73 K_{\text {eli }}}\right)^{-1} .
\end{aligned}
$$

The oil film stiffness between the rolling element and the outer race, $k_{E H L}^{o}$, can be calculated in the same way. Thus, the total oil film stiffness of the bearing can be obtained:

$$
k_{b, j}^{E}=\left(\frac{1}{k_{E H L}^{i}}+\frac{1}{k_{E H L}^{o}}\right)^{-1} .
$$

The global stiffness of the rolling element can be obtained:

$$
k_{b, j}=\left(\frac{1}{k_{b, j}^{H}}+\frac{1}{k_{b, j}^{E}}\right)^{-1}
$$

Accordingly, the radial contact load of a rolling element can be calculated as

$$
Q_{b, j}^{i}=k_{b, j} \cdot \delta_{b, j}
$$

Then the supporting forces of the ball bearing in the $y$ - and $x$-directions are given as

$$
\begin{aligned}
& F_{b, y}=-Q_{b} \frac{y}{\delta_{b}}, \\
& F_{b, x}=-Q_{b} \frac{x}{\delta_{b}} .
\end{aligned}
$$

2.2.2. Bearing Model with Inner Race Defect. When defect occurred on inner race of bearing, Figure 2 was transferred into Figure 3 in detail. The displacement of the $i$ th rolling element can be calculated as [6]

$$
r_{j}=x \cos \theta_{j}+y \sin \theta_{j}-\mu_{b}-\mu_{\text {inner }},
$$




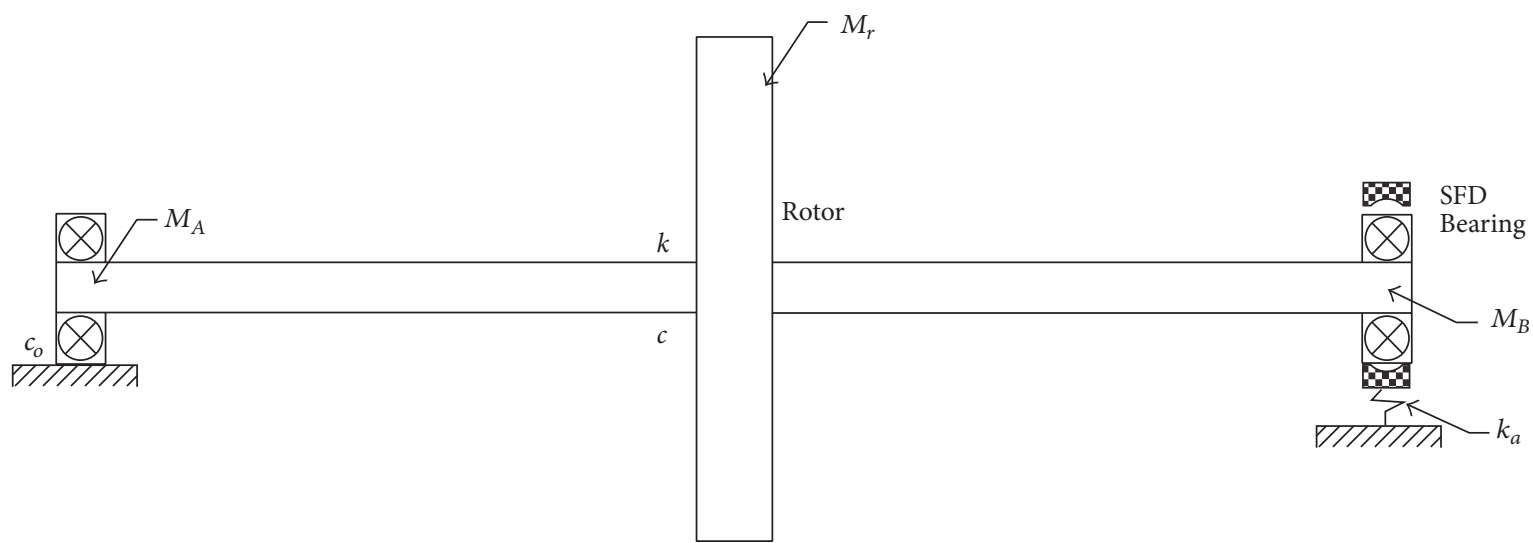

FIgURE 4: The model of the rotor-bearing-SFD system.

where $\mu_{\text {inner }}$ is the additional displacement of the rolling element due to the inner race defect which is given as

$$
\mu_{\text {inner }}=R_{\text {inner }}-\sqrt{R_{\text {inner }}^{2}-\left(\frac{L_{i}}{2}\right)^{2}},
$$

where $D_{b}$ is the radius of the rolling element and $L_{i}$ is the width of the defect on inner race.

The contact angle, $\theta_{i}$, of the $i$ th rolling element and the defect angle, $\Phi_{i}$, are given as

$$
\begin{aligned}
\theta_{j} & =\frac{2 \pi}{N}(t-1)+\omega_{\text {cage }} t \\
\Phi_{j} & =\arcsin \frac{L_{i}}{2 R_{\text {inner }}},
\end{aligned}
$$

where $N$ is the number of the rolling element, $\omega_{\text {cage }}$ is the angular velocity of the cage, and $R_{\text {inner }}$ is the radius of the defect.

$$
\omega_{\text {cage }}=\omega_{\text {rotor }} \frac{r}{R+r},
$$

where $R$ and $r$ are the radiuses of the outer and the inner races, respectively.

Substituting Eq. (12)-(15), the additional displacement of the rolling element, $\mu_{\text {inner }}$, per cycle can be obtained:

$$
\begin{aligned}
& \mu_{\text {inner }} \\
& = \begin{cases}R_{\text {inner }}-\sqrt{{R_{\text {inner }}}^{2}-\left(\frac{L_{i}}{2}\right)^{2}} & 0<\bmod \left(\frac{\theta_{j}}{2 \pi}\right)-\theta_{\text {inner }}<\Phi_{j} \\
0 & \text { otherwise. }\end{cases}
\end{aligned}
$$

2.3. Rotor System Model. The rotor-bearing-SFD system is developed based on the Jeffcott rotor (shown in Figure 4) in which the ball bearing $B$ (on the right end) has the inner race defect and the SFD is mounted on one bearing at a time (e.g., the SFD was mounted on bearing $B$ in Figure 4 , and in this paper, the SFD mounted both $A$ and $B$ were discussed). The model is established based on the following assumptions:

(1) The movements of the rotor in axial and torsional directions are negligible.
(2) Each lumped mass point has four degrees of freedom including two translations and two rotations.

(3) The mass of spindle is lumped at the location of two bearings and the rotor mass is lumped at a point at the middle of the rotor.

The equations of motion of the dynamic system are derived as

$$
\begin{aligned}
& m_{r} \ddot{x}_{r}+c \dot{x}_{r}+k\left(x_{r}-x_{A}\right)+k\left(x_{r}-x_{B}\right) \\
& =m_{r} e \omega^{2} \cos \theta, \\
& m_{r} \ddot{y}_{r}+c \dot{y}_{r}+k\left(y_{r}-y_{A}\right)+k\left(y_{r}-y_{B}\right) \\
& =m_{r} e \omega^{2} \sin \theta-m g, \\
& m_{A} \ddot{x}_{A}+c_{o} \dot{x}_{A}+k\left(x_{A}-x_{r}\right)=F_{A(b, x)}, \\
& m_{A} \ddot{y}_{A}+c_{o} \ddot{y}_{A}+k\left(y_{A}-y_{r}\right)=F_{A(b, y)}-m_{A} g, \\
& m_{B} \ddot{x}_{B}+c_{o} \dot{x}_{B}+k\left(x_{B}-x_{r}\right)=F_{B(b, x)}, \\
& m_{B} \ddot{y}_{B}+c_{o} \ddot{y}_{B}+k\left(y_{B}-y_{r}\right)=F_{B(b, y)}-m_{B} g, \\
& m_{s} \ddot{x}_{s}+k_{a} x_{s}=F_{s, x}-F_{B(b, x)}, \\
& m_{s} \ddot{y}_{s}+k_{a} y_{s}=F_{s, y}-F_{B(b, y)}-m_{s} g,
\end{aligned}
$$

where $m_{r}, m_{A}$, and $m_{B}$ are the lumped masses of the rotor at the disk and the bearing positions respectively, $c$ and $c_{o}$ are viscous damping factors of the disk and the bearing, respectively, $k$ is the stiffness of the shaft, $F_{A(b, x)}, F_{A(b, y)}$, $F_{B(b, x)}$, and $F_{B(b, y)}$ are the supporting forces of the bearings in the $x$-and $y$-directions, $m_{s}$ is the lumped mass of the bearing outer race, $k_{a}$ is the supporting stiffness of the SFD, and $F_{s, x}$ and $F_{s, y}$ are the supporting forces of the SFD in the $x$ - and $y$-directions.

2.4. Numerical Method and Simulation Parameters. In the paper, the differential equations of motion are solved by the Runge-Kutta method. The time step of the iterative procedure is $\Delta t=1 \times 10^{-5} \mathrm{~s}$. The time-varying data corresponding to 


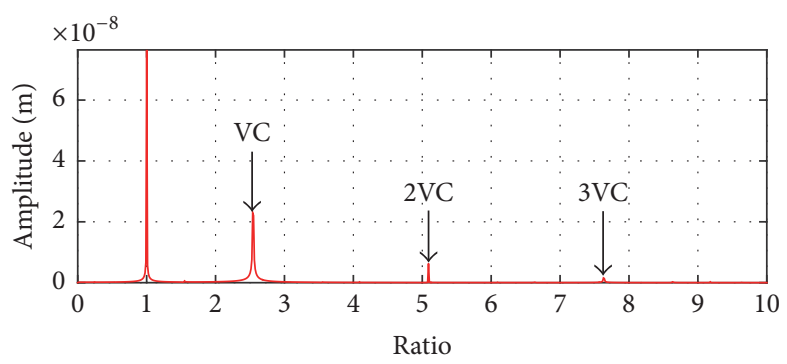

(a)

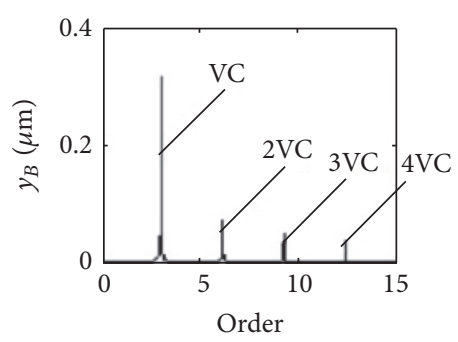

(b)

FIgURE 5: Rotor response of frequency spectrum (a) in this paper (b) in [11].

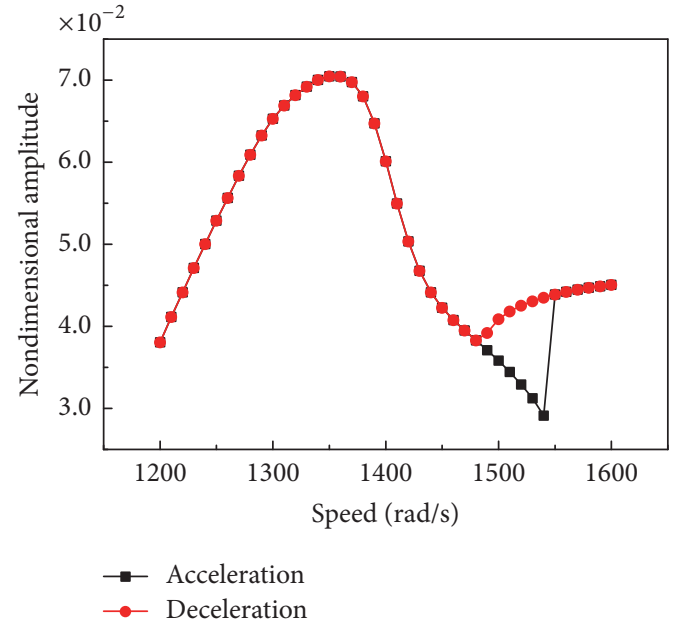

(a)

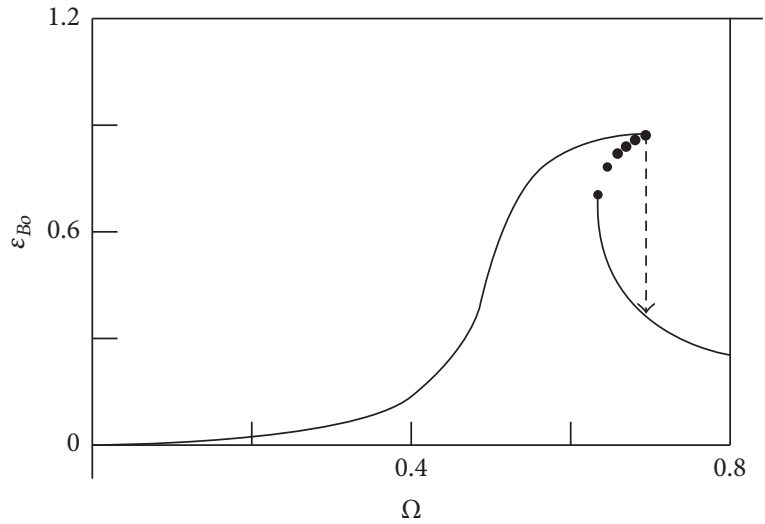

(b)

FIGURE 6: Steady state responses of rotor in this paper (a) in this paper (b) in [22].

the first 500 periods generated by the numerical integration is deliberately excluded in order to discard the transient solutions. The parameters of the system are shown as follows:

Parameters of the System

$$
\begin{aligned}
& d_{m}: 47 e-3 \mathrm{~m} \\
& D_{b}: 8.731 e-3 \mathrm{~m} \\
& m_{r}: 15 \mathrm{~kg} \\
& m_{A}: 1 \mathrm{~kg} \\
& m_{B}: 1 \mathrm{~kg} \\
& c: 1500 \mathrm{~N} * \mathrm{~s} / \mathrm{m} \\
& c_{o}: 2100 \mathrm{~N} * \mathrm{~s} / \mathrm{m} \\
& k_{a}: 2 e 6 \mathrm{~N} / \mathrm{m} \\
& k: 2.5 e 7 \mathrm{~N} / \mathrm{m} \\
& \mu_{s}: 0.02 \mathrm{~Pa} * \mathrm{~S} \\
& c_{s}: 8 e-5 \mathrm{~m} \\
& l_{s}: 11 e-3 \mathrm{~m} \\
& R_{s}: 0.03 \mathrm{~m}
\end{aligned}
$$

\section{Results and Discussion}

\subsection{Model Validation}

3.1.1. Bearing Model. In [12], a ball bearing dynamic model was established by Zhou et al. In order to validate the ball bearing dynamic model the simulation results of the model should be compared with the results of [12] on the same computation conditions. In this paper, the response of the rotor is shown in Figure 5; it is easy to find the VC frequency and 2, $3 \mathrm{VC}$ frequency which represents the ball passage frequency. The same conclusion was found in [12]; therefore, the model established in this paper is further validated.

3.1.2. SFD Model. In [23], the dynamic model of an unbalanced rotor supported on SFD without ball bearing was established by Zhu et al.; analytical method and numerical integration method were employed to obtain the responses of the rotor system. In order to validate the ball bearing dynamic model, the simulation results of the model should be compared with the results of [23] on the same computation conditions. It is shown in Figure 6 that the rotor system has multiple solutions in the region of $(1480,1550) \mathrm{rad} / \mathrm{s}$. The same phenomenon of multiple solution was found in [23]. 


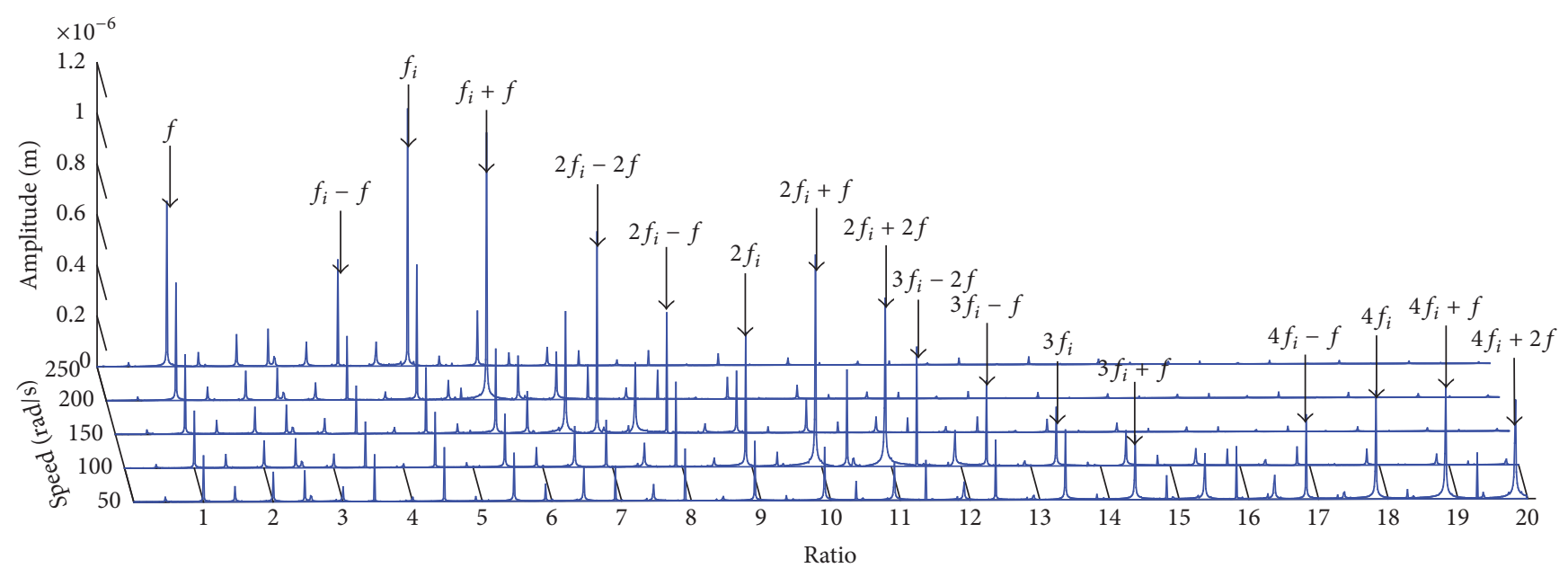

FIGURE 7: Waterfall plot of inner race defect bearing system with speed at width $1 e-3 \mathrm{~m}$.

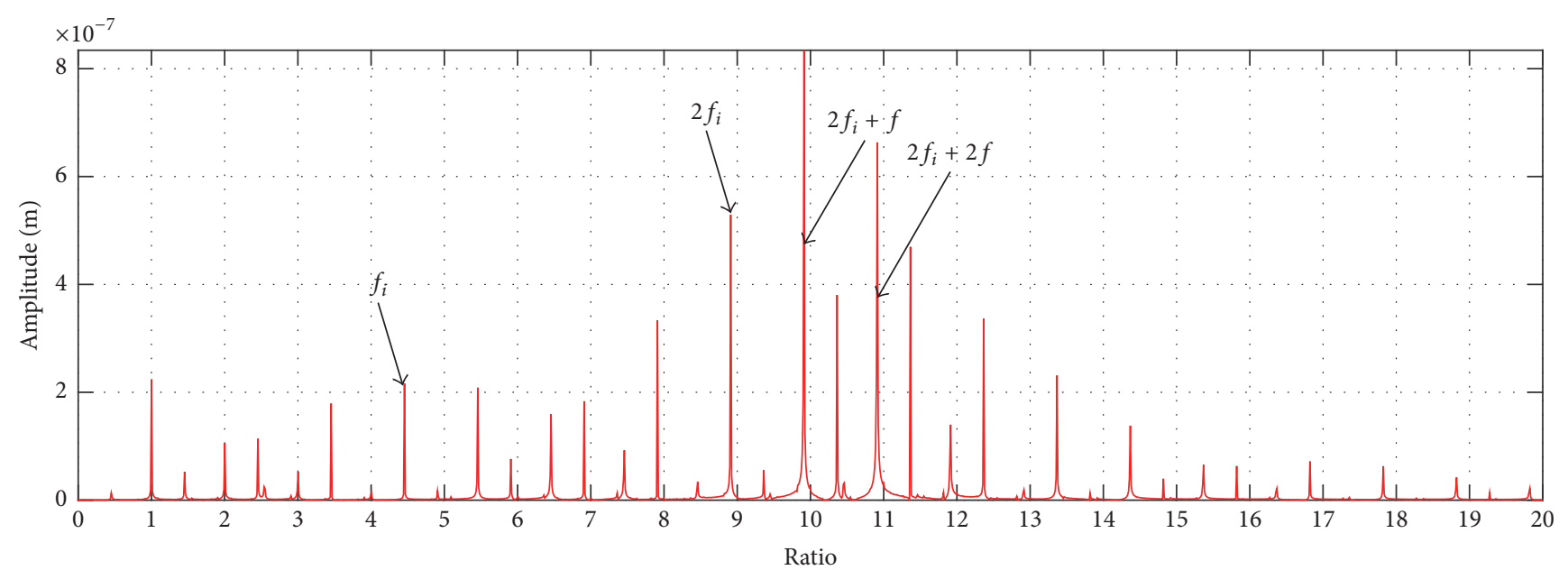

FIGURE 8: The spectral diagrams of the fault system with bearing inner race defect at $\omega=100 \mathrm{rad} / \mathrm{s}$ and width $1 e-3 \mathrm{~m}$.

By using this method, the model established in this paper is validated.

\subsection{Effects of Inner Race Defect}

3.2.1. Effects of Rotating Speed. For a ball bearing, the characteristic frequency of the inner race $\operatorname{defect} f_{i}$ can be calculated as

$$
f_{i}=\frac{N}{2}\left(1+\frac{D_{b}}{D_{m}}\right) \cdot f
$$

where $D_{b}$ is the diameter of the rolling element, $D_{m}$ is the pitch diameter of the bearing, $N$ is the number of the rolling elements, and $f$ is the rotating frequency of the rotor.

In order to study the fault characteristics of the bearing inner race defect, the waterfall plot of the faulted rotor system in the range of $(50,250) \mathrm{rad} / \mathrm{s}$ was shown in Figure 7 . When the speed is at $50 \mathrm{rad} / \mathrm{s}$, the maximum frequency is $4 f_{i}+f$ $(4.5 e-7 \mathrm{~m})$, the maximum frequency became $f_{i}(1.01 e-6 \mathrm{~m})$ at $250 \mathrm{rad} / \mathrm{s}$, and it can be found that, with the increasing of speed, the amplitude of high frequencies higher than $10 \mathrm{x}$ fundamental frequency decreased obviously, the maximum frequency moved to low frequency, and the amplitude of the maximum frequency had great increasing.

From Figure 8, when the speed is at $100 \mathrm{rad} / \mathrm{s}$, many multiple frequency components appear due to the inner race defect, in which the dominant peaks at $2 f_{i}, 2 f_{i}+f$ and $2 f_{i}+2 f$ are much higher than that at the fundamental frequency. In addition, the amplitudes at $3 f_{i}-f$ and $2 f_{i}-f$ are also greater than that at the fundamental frequency. Among the frequency components, the maximum amplitude at $2 f_{i}+f$ $\left(8.1 \times 10^{-7} \mathrm{~m}\right)$ is nearly four times that at the fundamental frequency. Besides, the sideband frequencies centering on $f_{i}$ and its multiple frequencies with an interval $f$ (e.g., $2 f_{i}-f$, $\left.2 f_{i}+f\right)$ can be found in the faulted rotor system.

At $150 \mathrm{rad} / \mathrm{s}$ case, in Figure 9 for the faulted system, three dominant frequency components can be found which are $2 f_{i}-2 f, f_{i}+2 f$, and $2 f_{i}-f$. The maximum amplitude is nearly $7.9 e-7 \mathrm{~m}$ at $2 f_{i}-2 f$ which is far higher than 


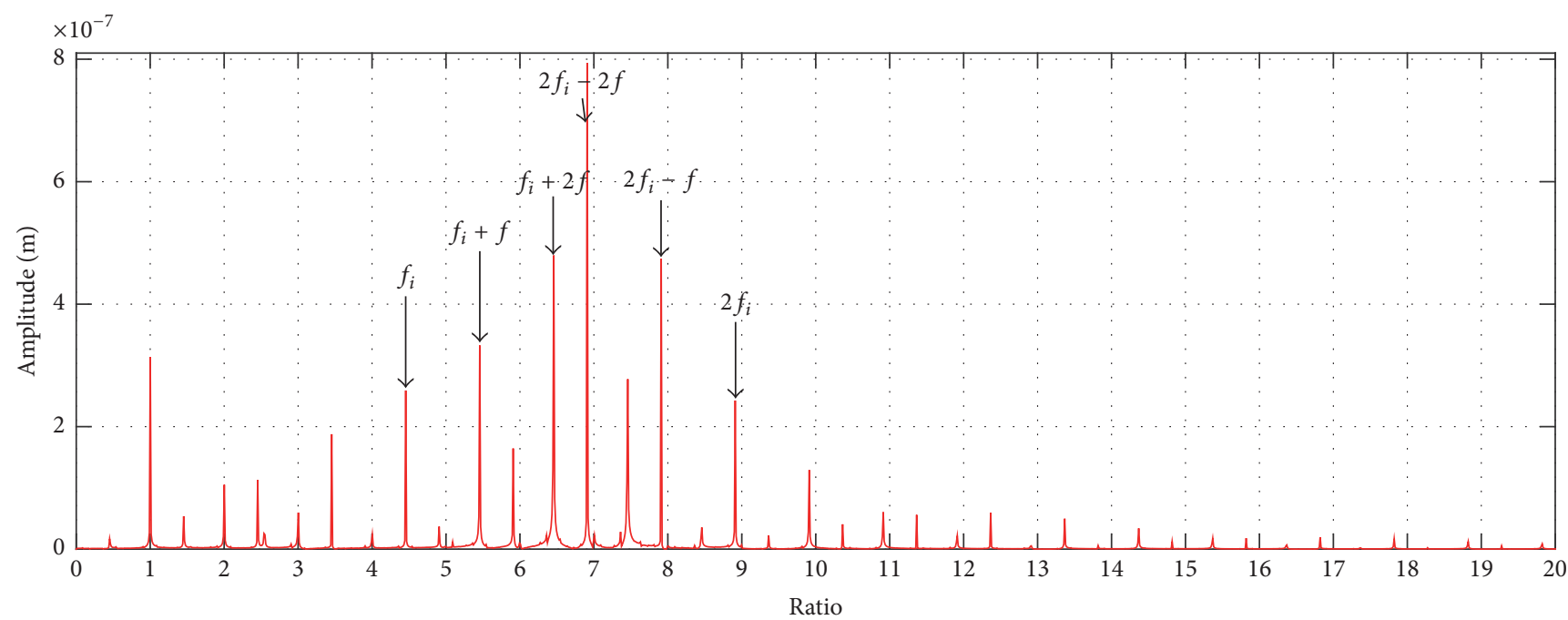

FIGURE 9: The spectral diagrams of the fault system with bearing inner race defect at $\omega=150 \mathrm{rad} / \mathrm{s}$ and width $1 e-3 \mathrm{~m}$.

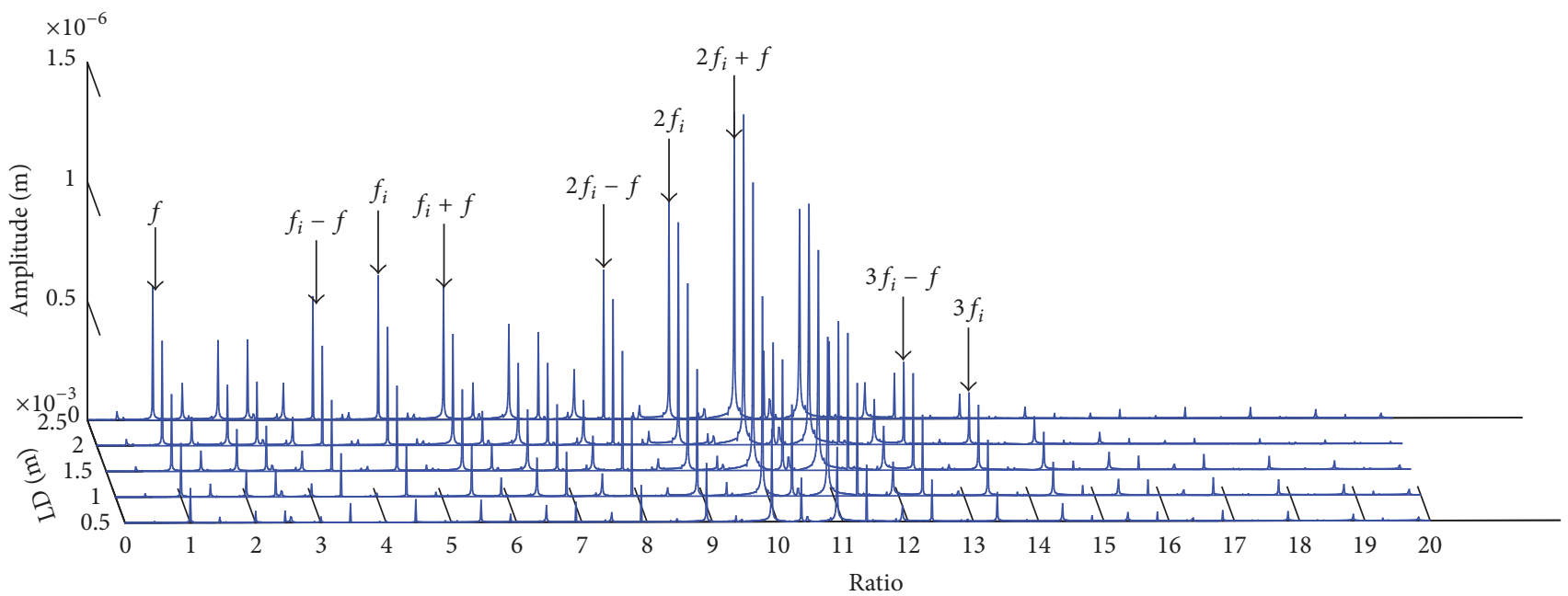

FIGURE 10: Waterfall plot of inner race defect bearing system with width of defect at $100 \mathrm{rad} / \mathrm{s}$.

the fundamental frequency. Similar to the $100 \mathrm{rad} / \mathrm{s}$ case, sideband frequencies from $f_{i}$ to $2 f_{i}$ can be found. Comparing to the faulted system at $100 \mathrm{rad} / \mathrm{s}$, the amplitudes at the sideband frequencies increased while that centering at $2 f_{i}$ decreased.

By analyzing these pictures, it can be concluded that the fault characteristics of the bearing inner race defect are significant at a lower rotating speed of the rotor system. With increasing speed, the significance of the bearing fault characteristic becomes much lower due to the amplitude of the fundamental frequency increases greatly, while that of the fault characteristic frequencies only has a very slight increment.

3.2.2. Effects of Defects Width. From Figure 10, it is found that the maximum frequency is $2 f_{i}+f$ no matter how width changed, with the increasing of width in range of $(0.5 e-3 \mathrm{~m}$,
$2 e-3 \mathrm{~m}$ ), the amplitude of $2 f_{i}+f$ is increased from $3.87 e-7 \mathrm{~m}$ to $1.381 e-6 \mathrm{~m}$, with a little decrease when width at $2.5 e-$ $3 \mathrm{~m}$. The sideband besides $f_{i}$ has great increasing while it, besides $3 f_{i}$, has no obvious changing. From Figure 11, the same phenomenon is found, only the maximum frequency is $2 f_{i}-2 f$, and it increased from $3.67 e-7 \mathrm{~m}$ (at $0.5 e-3 \mathrm{~m}$ ) to $1.569 e-6 \mathrm{~m}$ (at $2.5 e-3 \mathrm{~m}$ ). From Figures 10 and 11, it can be found that the width of defect has great influence to the amplitude of frequency. With the increasing of width, the amplitude has great change. But the width has no obvious effect to the distribution of frequency.

\subsection{Effects of SFD}

3.3.1. SFD Mounted on Bearing A. To study the effect of the SFD on the dynamic behavior of the rotor system with bearing fault, the SFD is mounted on one of the two bearings 


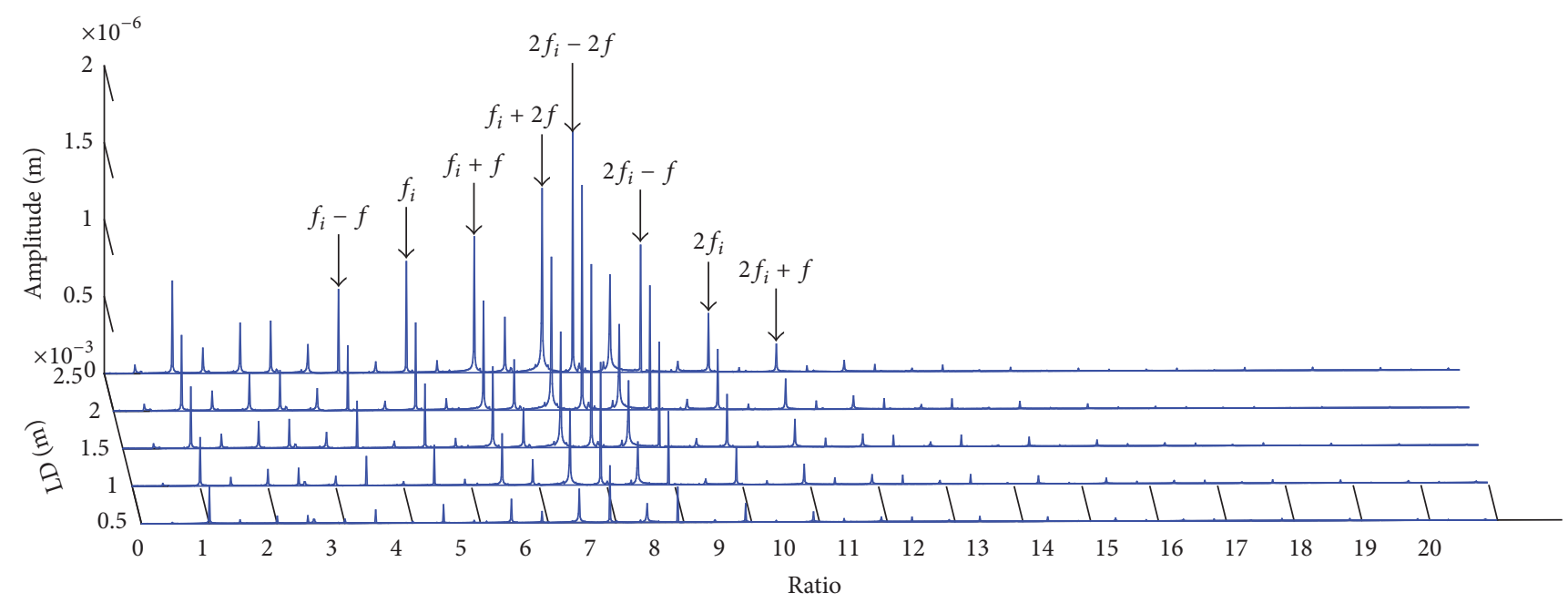

FIGURE 11: Waterfall plot of inner race defect bearing system with width of defect at $150 \mathrm{rad} / \mathrm{s}$.

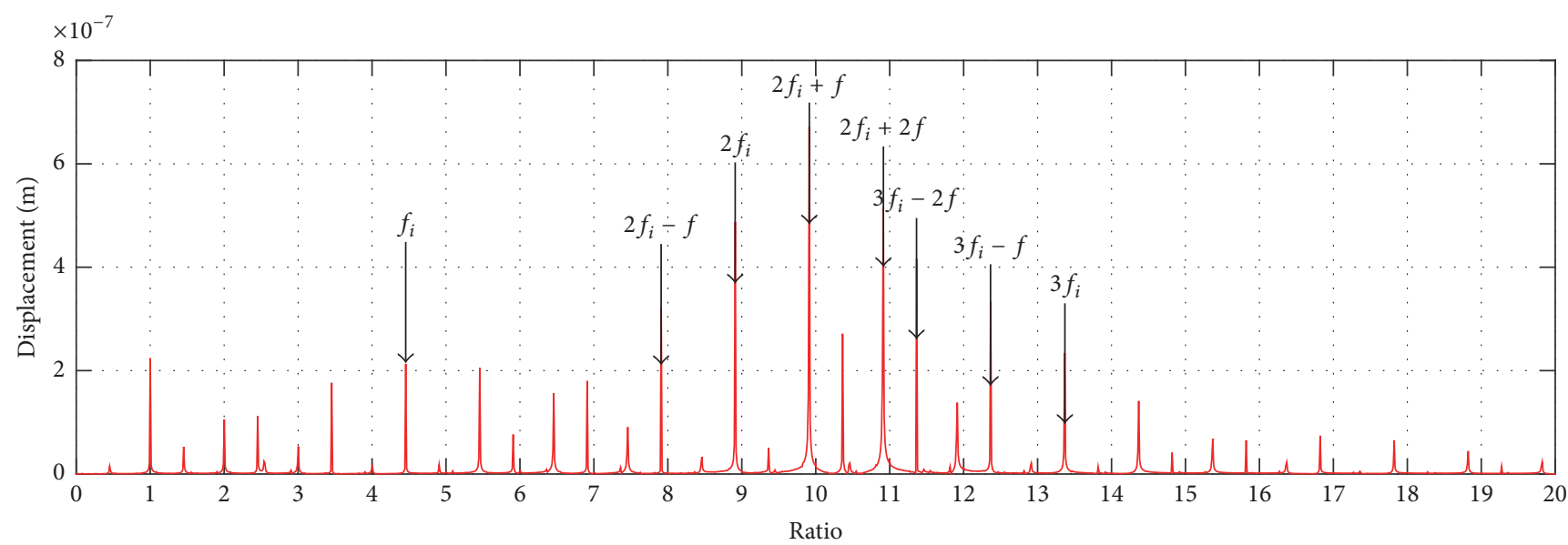

FIGURE 12: The spectral diagrams of the faulted system with SFD mounted on the normal bearing at $\omega=100 \mathrm{rad} / \mathrm{s}$ and width $=1 e-3 \mathrm{~m}$.

at a time. The spectral diagrams of the faulted system with the SFD mounted on the normal bearing at the speed of $100 \mathrm{rad} / \mathrm{s}$, $150 \mathrm{rad} / \mathrm{s}$ are shown in Figures 12 and 13.

Comparing with the system without SFD (Figure 8), it can be found that the amplitude of the fundamental frequency does not change, while the amplitudes at the fault characteristic frequencies and the sideband frequencies are decreased. For instance, the amplitude at $2 f_{i}+f$ decreased from $8.1 \times 10^{-7} \mathrm{~m}$ to $6.7 \times 10^{-7} \mathrm{~m}$, that at $2 f_{i}$ decreased from $5.3 \times 10^{-7} \mathrm{~m}$ to $4.8 \times 10^{-7} \mathrm{~m}$, and that at $2 f_{i}+2 f$ decreased from $6.6 \times 10^{-7} \mathrm{~m}$ to $5.3 \times 10^{-7} \mathrm{~m}$, while the maximum frequency still locates at $2 f_{i}+f$ the same as the system without SFD. It can be seen that the introduction of the SFD on the normal bearing does not have much effect on the frequency characteristics of the rotor system at low speed.

3.3.2. SFD Mounted on Bearing B. Figures 13-15 are the spectral diagrams of the rotor system with the SFD mounted on the fault bearing at $100 \mathrm{rad} / \mathrm{s}$ and $150 \mathrm{rad} / \mathrm{s}$, respectively.
It can be seen that the amplitude at the fundamental frequency declines from $2.2 \times 10^{-7} \mathrm{~m}$ (shown in Figure $7(\mathrm{~b})$ ) to $1.5 \times 10^{-7} \mathrm{~m}$ (shown in Figure 13) when the rotating speed is $100 \mathrm{rad} / \mathrm{s}$. The amplitudes at the fault characteristic frequencies also decrease a lot, such as from $8.1 \times 10^{-7} \mathrm{~m}$ to $1.52 \times 10^{-7} \mathrm{~m}$ at $2 f_{i}+f$, from $5.3 \times 10^{-7} \mathrm{~m}$ to $1.9 \times 10^{-7} \mathrm{~m}$ at $2 f_{i}$, and from $6.6 \times 10^{-7} \mathrm{~m}$ to $6.5 \times 10^{-8} \mathrm{~m}$ at $2 f_{i}+2 f$. In addition, dominant frequency shifts to $2 f_{i}$.

At $150 \mathrm{rad} / \mathrm{s}$ case, the amplitude of the fundamental frequency of the system with the SFD mounted on the faulted bearing does not change much comparing with that without the SFD. However, the amplitudes at fault characteristic frequencies decrease significantly due to the adoption of the SFD (from $1.04 \times 10^{-6} \mathrm{~m}$ to $1.02 \times 10^{-7} \mathrm{~m}$ at $f_{i}+f$ and from $5.3 \times 10^{-7} \mathrm{~m}$ to $2.01 \times 10^{-7} \mathrm{~m}$ at $\left.f_{i}\right)$. Apart from that, the amplitudes at fault characteristic frequencies are even smaller than that of the fundamental frequency which may be a considerable influence on system response caused by the SFD mounted on the faulted bearing. It is found that the 


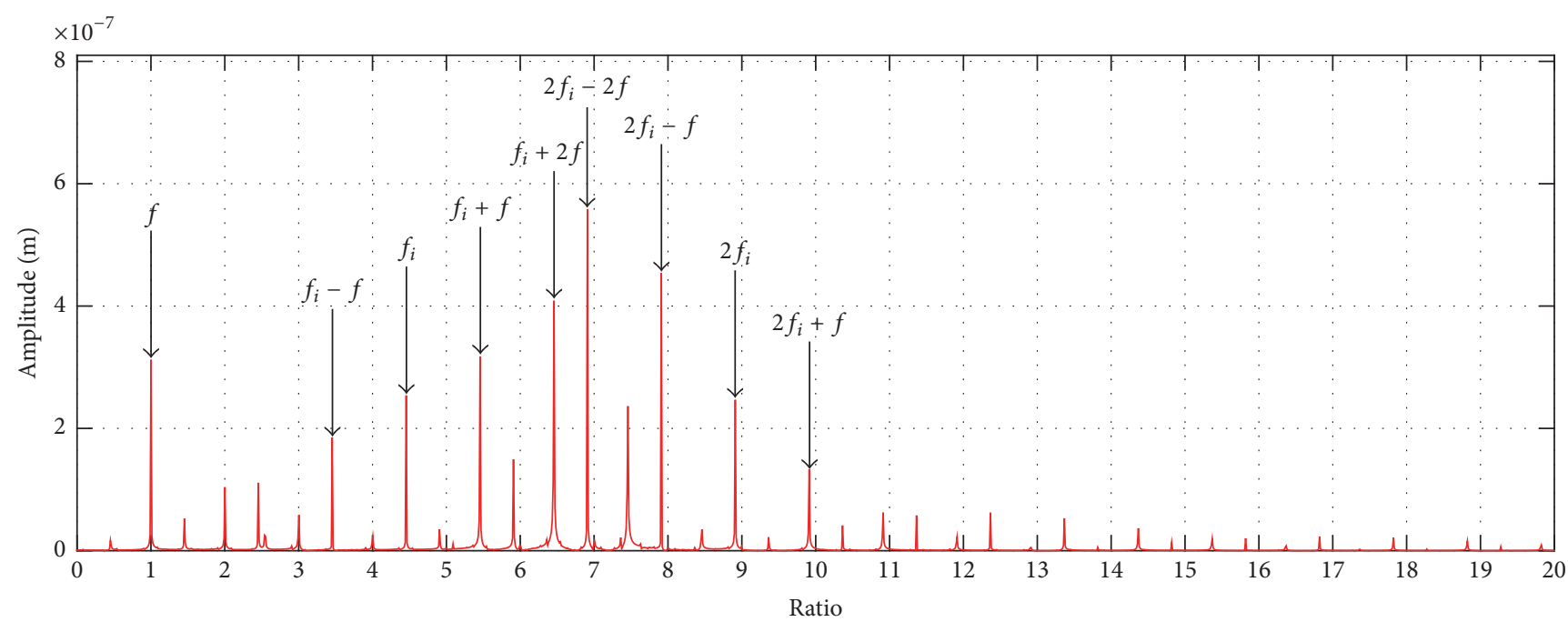

FIGURE 13: The spectral diagrams of the faulted system with SFD mounted on the normal bearing at $\omega=150 \mathrm{rad} / \mathrm{s}$ and width $=1 e-3 \mathrm{~m}$.

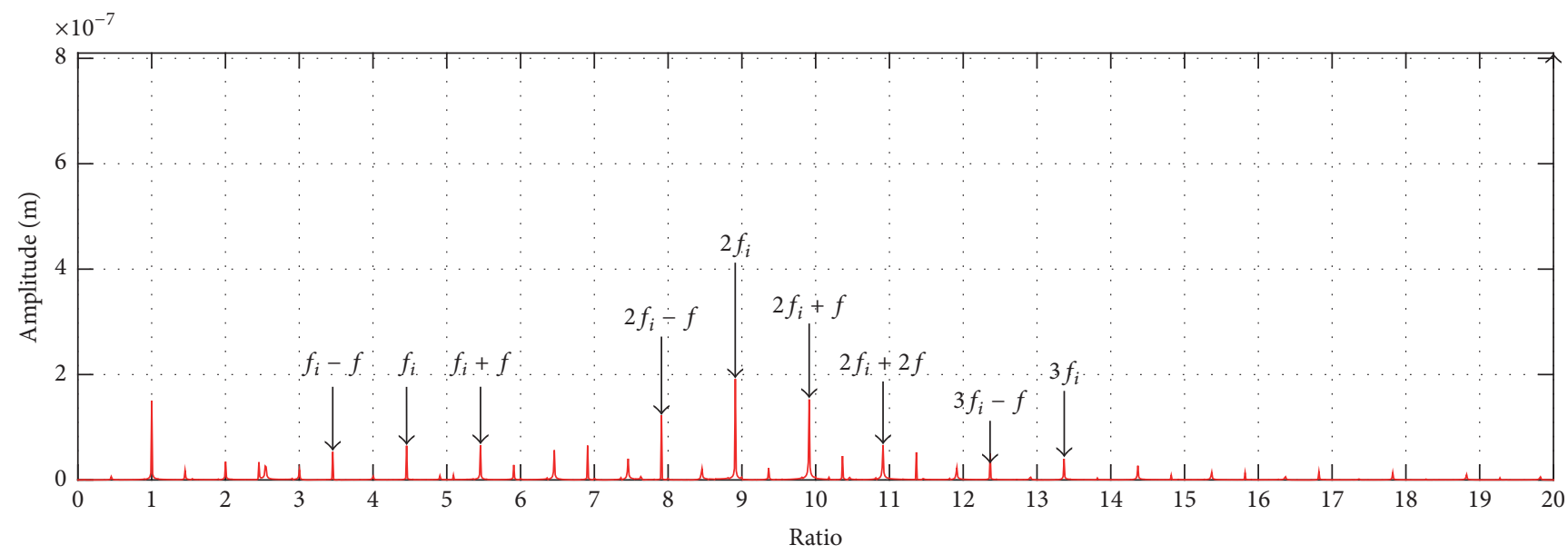

FIGURE 14: The spectral diagram of the faulted system with SFD mounted on the faulted bearing at $\omega=100 \mathrm{rad} / \mathrm{s}$.

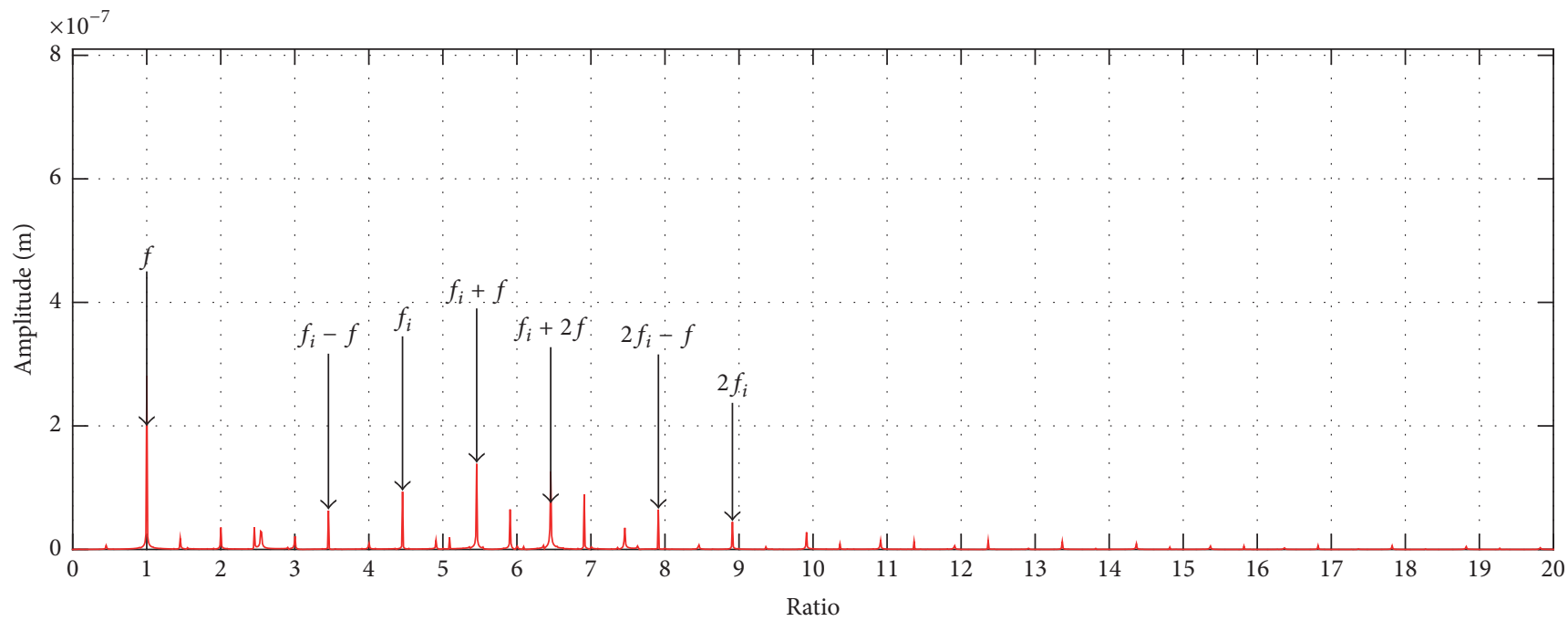

FIGURE 15: The spectral diagram of the faulted system with SFD mounted on the faulted bearing at $\omega=150 \mathrm{rad} / \mathrm{s}$. 


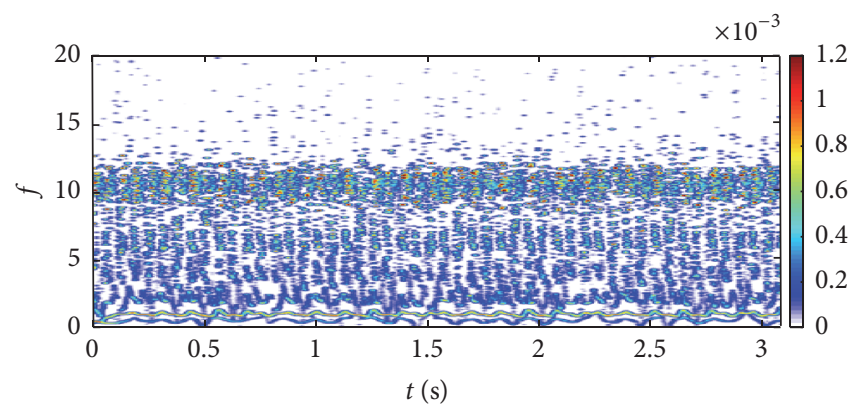

(a)

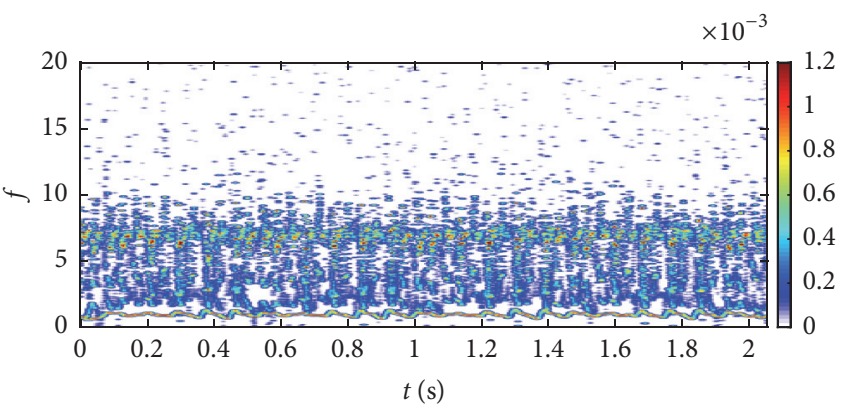

(b)

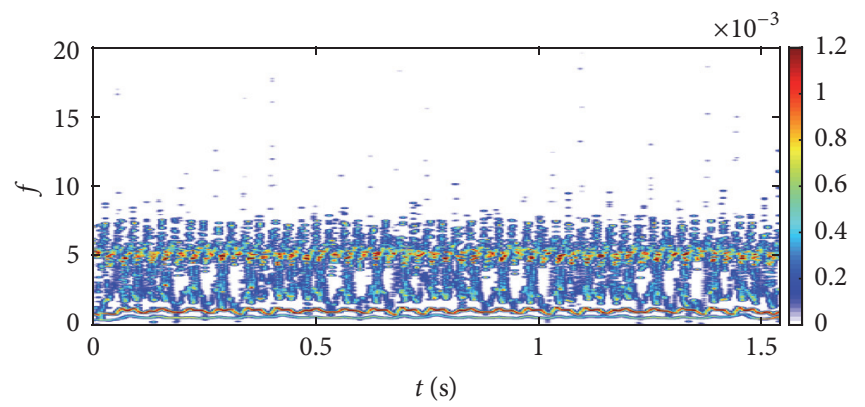

(c)

Figure 16: Time-frequency diagrams of the faulted system at (a) $100 \mathrm{rad} / \mathrm{s}$, (b) $150 \mathrm{rad} / \mathrm{s}$, and (c) $200 \mathrm{rad} / \mathrm{s}$.

stability of the rotor system is enhanced due to the fact that fault characteristics are suppressed a lot by the SFD on the faults side compared to the normal side.

\subsection{Time-Frequency Analysis}

3.4.1. For Effect of Faults Characteristics. Time-frequency diagrams of the faulted rotor system at different rotating speeds are shown in Figure 16. It is found that the energy of the signal concentrates around the 10x fundamental frequency, which is close to the peak at the $2 f_{i}+f$ frequency in the spectral diagram. The signal of the bearing fault performs as impacts in the high frequency range without any patterns, while the signal of the fundamental frequency is continuous in the same frequency range. Figure 16(b) indicates that the system energy centralizes at the fundamental frequency and between 5 and 10x fundamental frequency, and in Figure 16(c) the energy centralizes at $5 x$ fundamental frequency. The amplitude of the max energy has a little change with the speed increasing.

The time-frequency diagrams of the faulted rotor system at different defect width were shown in Figures 16 and 17. With the increasing of defects width, the distribution of signal energy changed a little, and the characteristic of the signal is changeless, but the amplitude of energy increased a lot with width increasing.

3.4.2. For Effect of SFD. Time-frequency diagrams of the faulted rotor system with the SFD mounted on bearing A (normal bearing) are shown in Figure 18. It can be seen that the rotor signal in high frequency range is still remittent, while the distribution of the signal energy is much looser with some components moving to the higher frequency at $100 \mathrm{rad} / \mathrm{s}$. With the speed increased to $200 \mathrm{rad} / \mathrm{s}$, the signal energy moves to $5 \mathrm{x}$ fundamental frequency $\left(f_{i}+f\right.$ in the spectral diagram), and the energy in high frequency is reduced. Thus the system signal energy does not show apparent changes when the SFD is mounted on the normal bearing side. Comparing to Figure 16, the energy of the signal has no obvious decreasing.

Time-frequency diagrams of the rotor system with the SFD mounted on the bearing B (faulted bearing) are shown in Figure 19. At low rotating speed, the energy of the signal decreases sharply especially at the frequency higher than $10 \mathrm{x}$ fundamental frequency $\left(2 f_{i}+f\right.$ in the spectral diagram). As the speed increased to $200 \mathrm{rad} / \mathrm{s}$, the energy of signal shifts to the fundamental frequency and that of the fault signal at high frequency reduces a lot.

\section{Conclusions}

(1) The characteristics of inner race defects on bearing can be concluded that there are all kinds of frequencies on the spectral diagram from low frequency to high frequency. Most of these frequencies are related to the characteristic multiple frequency of the inner race defect and the fundamental frequency. The signal of the bearing fault performs as impacts in the high frequency range without any patterns. 


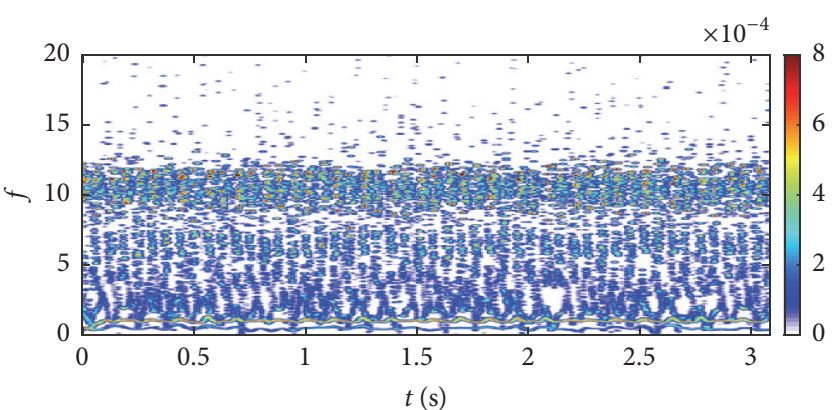

(a)

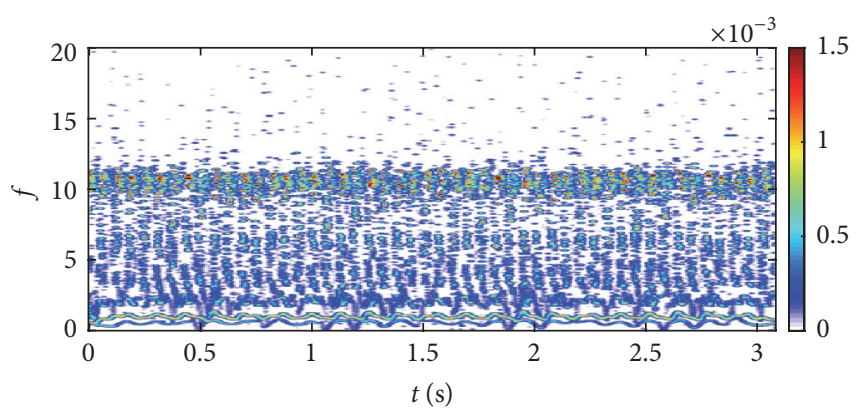

(c)

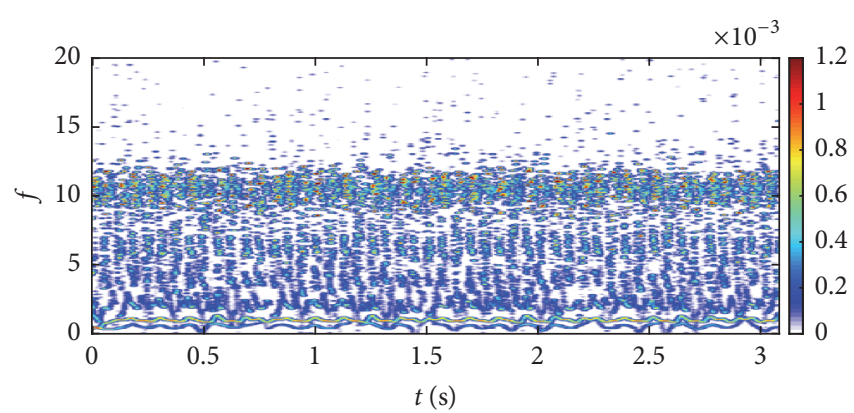

(b)

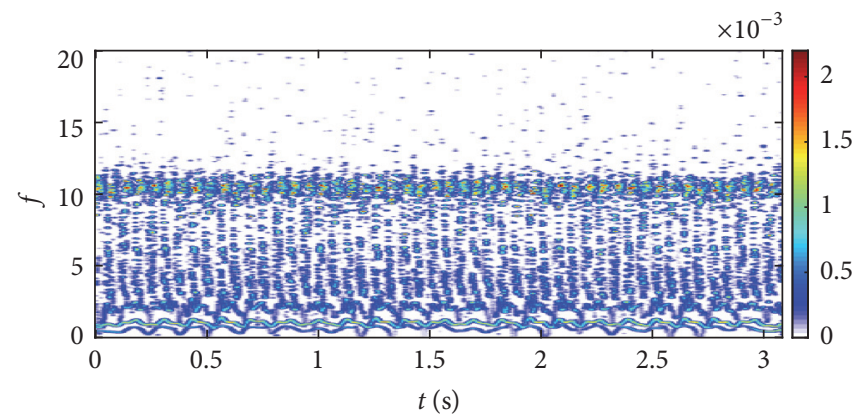

(d)

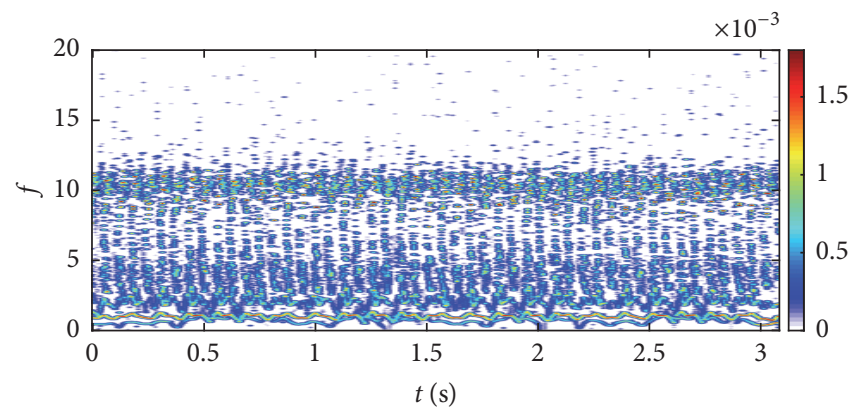

(e)

Figure 17: Time-frequency diagrams of the faulted system at $100 \mathrm{rad} / \mathrm{s}$ with different defect width: (a) $0.5 e-3 \mathrm{~m}$; (b) $1 e-3 \mathrm{~m}$; (c) $1.5 e-3 \mathrm{~m}$; (d) $2 e-3 \mathrm{~m}$; (e) $2.5 e-3 \mathrm{~m}$.

(2) The rotating speed and defect width had an obvious influence on the characteristics of inner race bearing. With the increasing of speed, the distribution of frequencies moves to the low frequency, and the amplitude of low frequency has great increasing, while the amplitude of the signal increases a little. With the increasing of the defect width, the amplitude of frequency and signal has great increasing while the distribution changes a little.

(3) The beneficial effect of the SFD strongly depends on the position of the SFD mounted. The vibration magnitudes of the rotor system show a slight decrease when the SFD is mounted on the unfaulted bearing while it is reduced significantly with the SFD mounted on the faulted bearing.

Comparing with the existing methods of analysis on bearing defects, this analysis of this paper is focused on studying the characteristics of frequency distribution and explored the laws where the frequencies changed with the length of bearing defects and speed. This paper also explored the effects of SFD to the bearing inner race defect frequencies.

\section{Competing Interests}

The authors declare that there is no conflict of interests regarding the publication of this paper.

\section{Acknowledgments}

The authors are grateful to the Joint Funds of National Science Foundation of China and Civil Aviation Administration Foundation of China (no. U1233201) and the Specialized Research Fund for the Doctoral Program of Higher Education (20130032130005) for providing financial support for this work. 


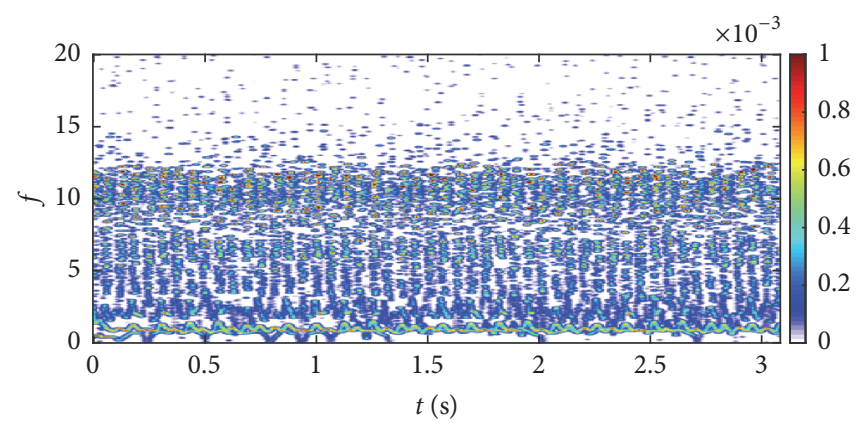

(a)

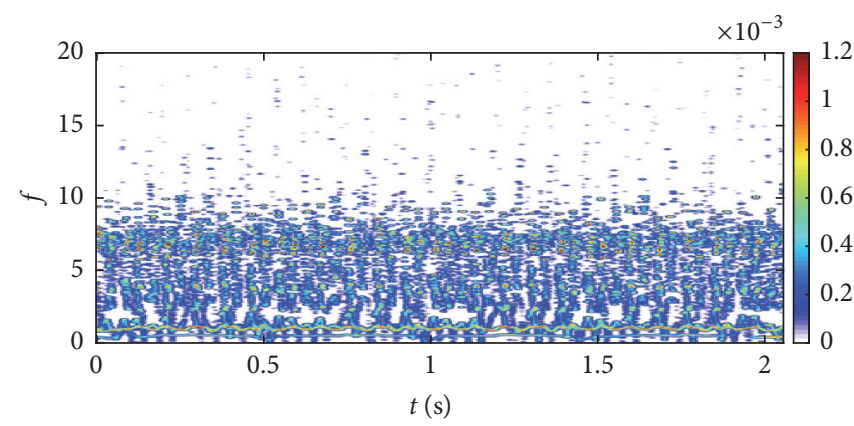

(b)

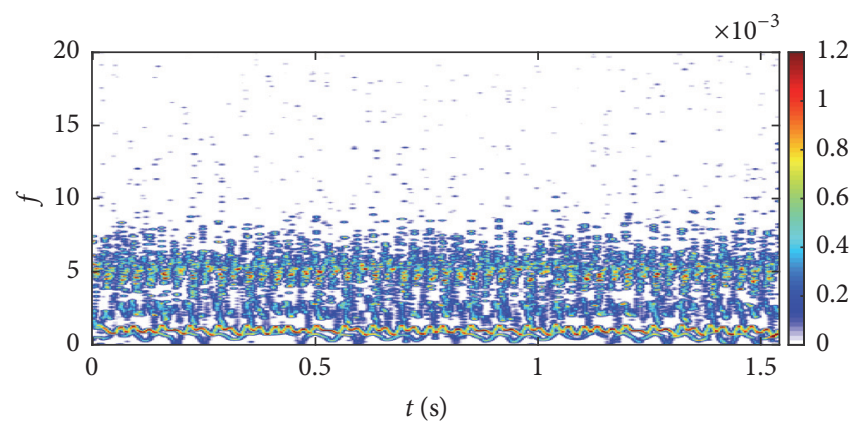

(c)

FIGURE 18: The time-frequency diagrams of the system with the SFD mounted on the normal bearing at (a) $100 \mathrm{rad} / \mathrm{s}$ and (b) $150 \mathrm{rad} / \mathrm{s}$ and (c) $200 \mathrm{rad} / \mathrm{s}$.

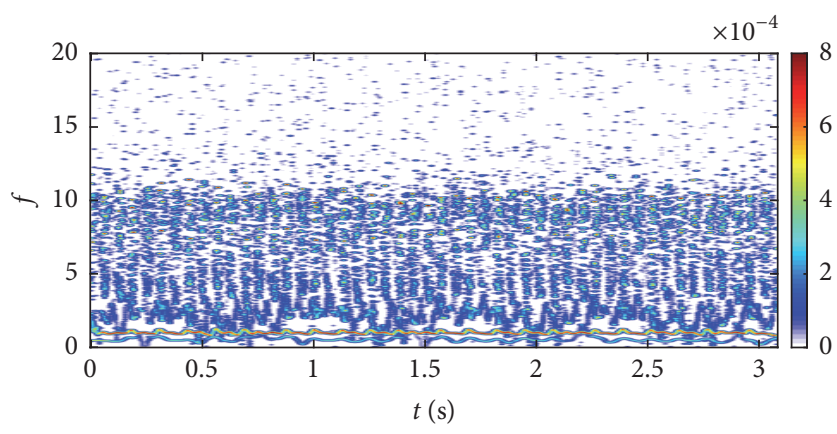

(a)

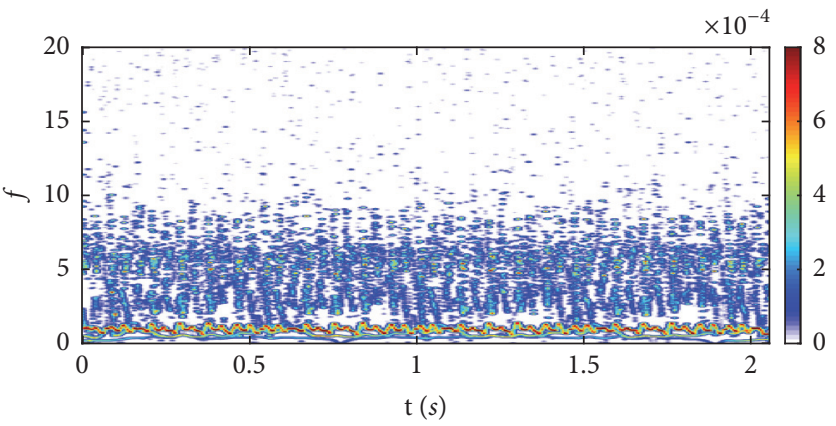

(b)

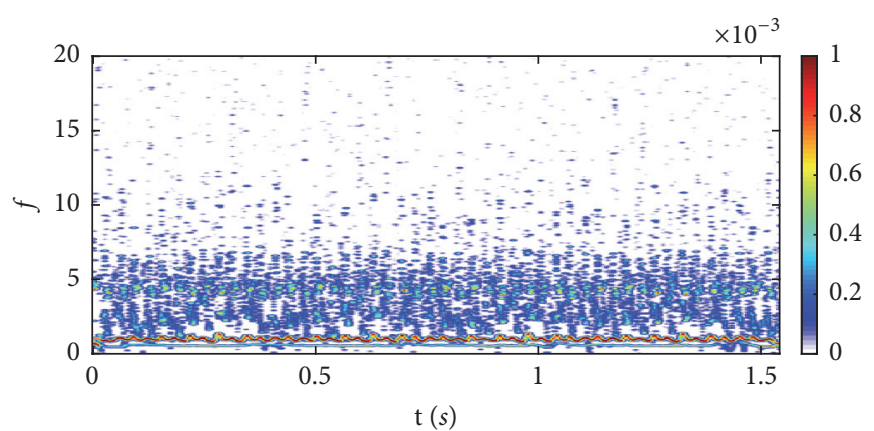

(c)

FIGURE 19: The time-frequency diagram of the system with the SFD mounted on the faulted bearing at (a) $100 \mathrm{rad} / \mathrm{s}$ and (c) $150 \mathrm{rad} / \mathrm{s}$ and (c) $200 \mathrm{rad} / \mathrm{s}$. 


\section{References}

[1] V. C. M. N. Leite, J. G. Borges Da Silva, G. F. C. Veloso et al., "Detection of localized bearing faults in induction machines by spectral kurtosis and envelope analysis of stator current," IEEE Transactions on Industrial Electronics, vol. 62, no. 3, pp. 18551865, 2015.

[2] A. K. S. Jardine, D. Lin, and D. Banjevic, "A review on machinery diagnostics and prognostics implementing condition-based maintenance," Mechanical Systems and Signal Processing, vol. 20, no. 7, pp. 1483-1510, 2006.

[3] X. Ding and Q. He, "Time-frequency manifold sparse reconstruction: a novel method for bearing fault feature extraction," Mechanical Systems and Signal Processing, vol. 80, pp. 392-413, 2016.

[4] W. Zhou, T. G. Habetler, and R. G. Harley, "Bearing fault detection via stator current noise cancellation and statistical control," IEEE Transactions on Industrial Electronics, vol. 55, no. 12, pp. 4260-4269, 2008.

[5] L. Frosini and E. Bassi, "Stator current and motor efficiency as indicators for different types of bearing faults in induction motors," IEEE Transactions on Industrial Electronics, vol. 57, no. 1, pp. 244-251, 2010.

[6] P. K. Kankar, S. C. Sharma, and S. P. Harsha, "Vibration based performance prediction of ball bearings caused by localized defects," Nonlinear Dynamics, vol. 69, no. 3, pp. 847-875, 2012.

[7] H. Arslan and N. Aktürk, "An investigation of rolling element vibrations caused by local defects," Journal of Tribology, vol. 130, no. 4, Article ID 041101, 2008.

[8] M. S. Patil, J. Mathew, P. K. Rajendrakumar, and S. Desai, "A theoretical model to predict the effect of localized defect on vibrations associated with ball bearing," International Journal of Mechanical Sciences, vol. 52, no. 9, pp. 1193-1201, 2010.

[9] X. Ding and Q. He, "Time-frequency manifold sparse reconstruction: a novel method for bearing fault feature extraction," Mechanical Systems and Signal Processing, vol. 80, pp. 392-413, 2016.

[10] H. Ma, T. Yu, Q. Han, Y. Zhang, B. Wen, and C. Xuelian, “Timefrequency features of two types of coupled rub-impact faults in rotor systems," Journal of Sound and Vibration, vol. 321, no. 3-5, pp. 1109-1128, 2009.

[11] R. Liu, B. Yang, X. Zhang, S. Wang, and X. Chen, "Timefrequency atoms-driven support vector machine method for bearings incipient fault diagnosis," Mechanical Systems and Signal Processing, vol. 75, pp. 345-370, 2016.

[12] H.-L. Zhou, G.-H. Luo, G. Chen, and F. Wang, "Analysis of the nonlinear dynamic response of a rotor supported on ball bearings with floating-ring squeeze film dampers," Mechanism and Machine Theory, vol. 59, pp. 65-77, 2013.

[13] C.-W. Chang-Jian, "Non-linear dynamic analysis of a HSFD mounted gear-bearing system," Nonlinear Dynamics, vol. 62, no. 1-2, pp. 333-347, 2010.

[14] H.-L. Zhou, G.-Q. Feng, G.-H. Luo, Y.-T. Ai, and D. Sun, “The dynamic characteristics of a rotor supported on ball bearings with different floating ring squeeze film dampers," Mechanism and Machine Theory, vol. 80, pp. 200-213, 2014.

[15] J. I. Inayat-Hussain, "Bifurcations in the response of a flexible rotor in squeeze-film dampers with retainer springs," Chaos, Solitons \& Fractals, vol. 39, no. 2, pp. 519-532, 2009.

[16] L. Ma, J. Zhang, J. Lin, J. Wang, and X. Lu, "Dynamic characteristics analysis of a misaligned rotor-bearing system with squeeze film dampers," Journal of Zhejiang University-SCIENCE A, vol. 17, no. 8, pp. 614-631, 2016.

[17] M. Nakhaeinejad and M. D. Bryant, "Dynamic modeling of rolling element bearings with surface contact defects using bond graphs," Journal of Tribology, vol. 133, no. 1, Article ID 011102, 2011.

[18] K. H. Groves and P. Bonello, "Improved identification of squeeze-film damper models for aeroengine vibration analysis," Tribology International, vol. 43, no. 9, pp. 1639-1649, 2010.

[19] C. J. Maday, "The foundation of the Sommerfeld transformation," Journal of Tribology, vol. 124, no. 3, pp. 645-646, 2002.

[20] M. Sarangi, B. C. Majumdar, and A. S. Sekhar, "Stiffness and damping characteristics of lubricated ball bearings considering the surface roughness effect. Part 1: theoretical formulation," Proceedings of the Institution of Mechanical Engineers, Part J: Journal of Engineering Tribology, vol. 218, no. 6, pp. 529-538, 2004.

[21] M. Sarangi, B. C. Majumdar, and A. S. Sekhar, "Stiffness and damping characteristics of lubricated ball bearings considering the surface roughness effect. Part 2. Numerical results and application," Proceedings of the Institution of Mechanical Engineers Part J: Journal of Engineering Tribology, vol. 218, no. 6, pp. 539547, 2004.

[22] Harris, Rolling Bearing Analysis, John Wiley \& Sons, New York, NY, USA, 1991.

[23] C. S. Zhu, D. A. Robb, and D. J. Ewins, "Analysis of the multiplesolution response of a flexible rotor supported on non-linear squeeze film dampers," Journal of Sound and Vibration, vol. 252, no. 3, pp. 389-408, 2002. 


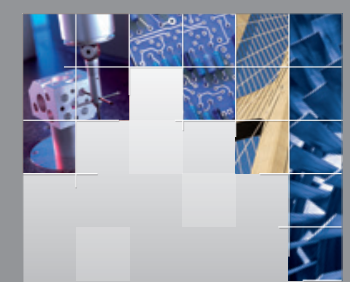

\section{Enfincering}
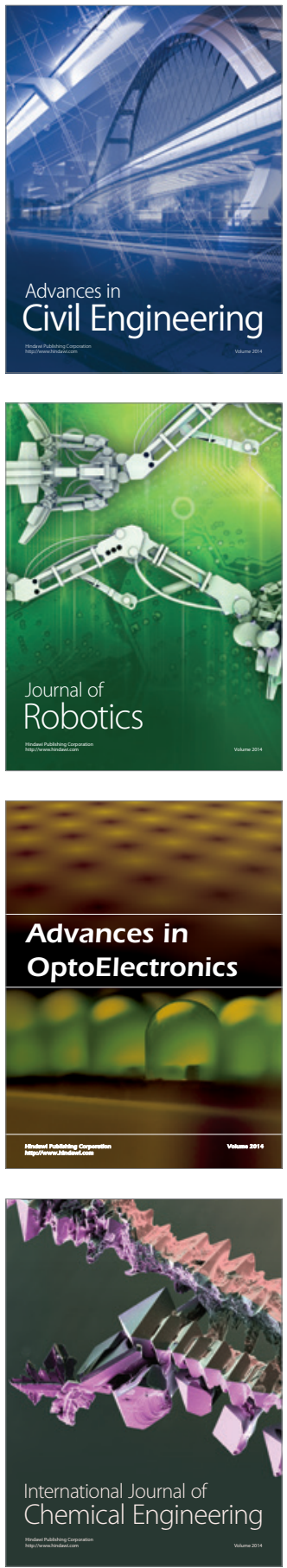

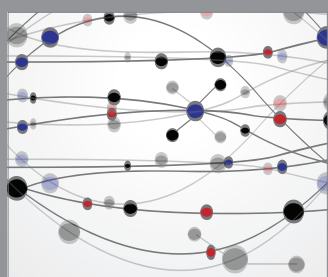

The Scientific World Journal

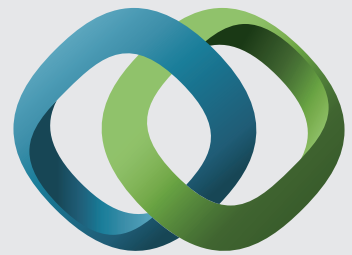

\section{Hindawi}

Submit your manuscripts at

https://www.hindawi.com
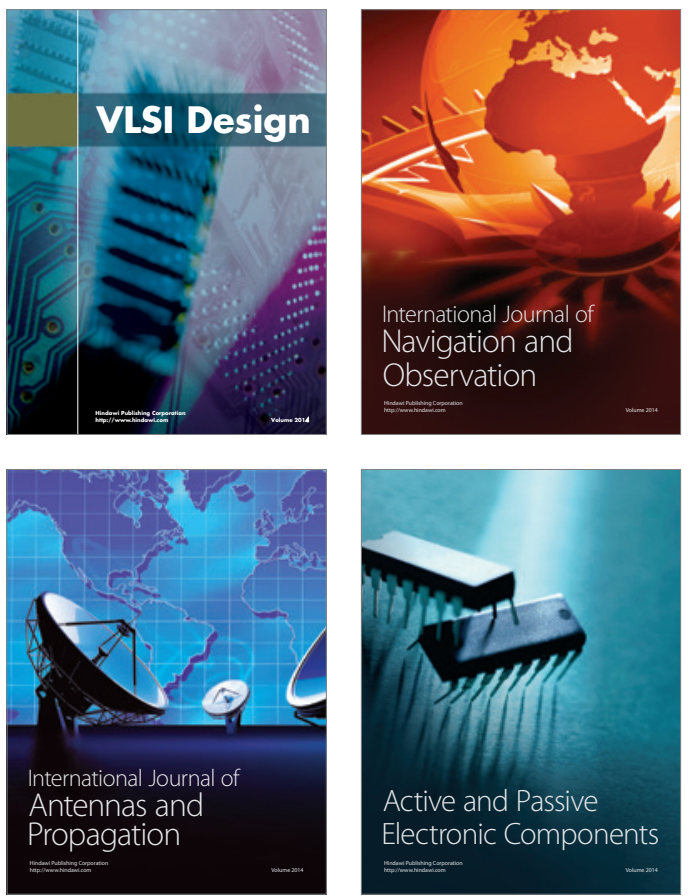
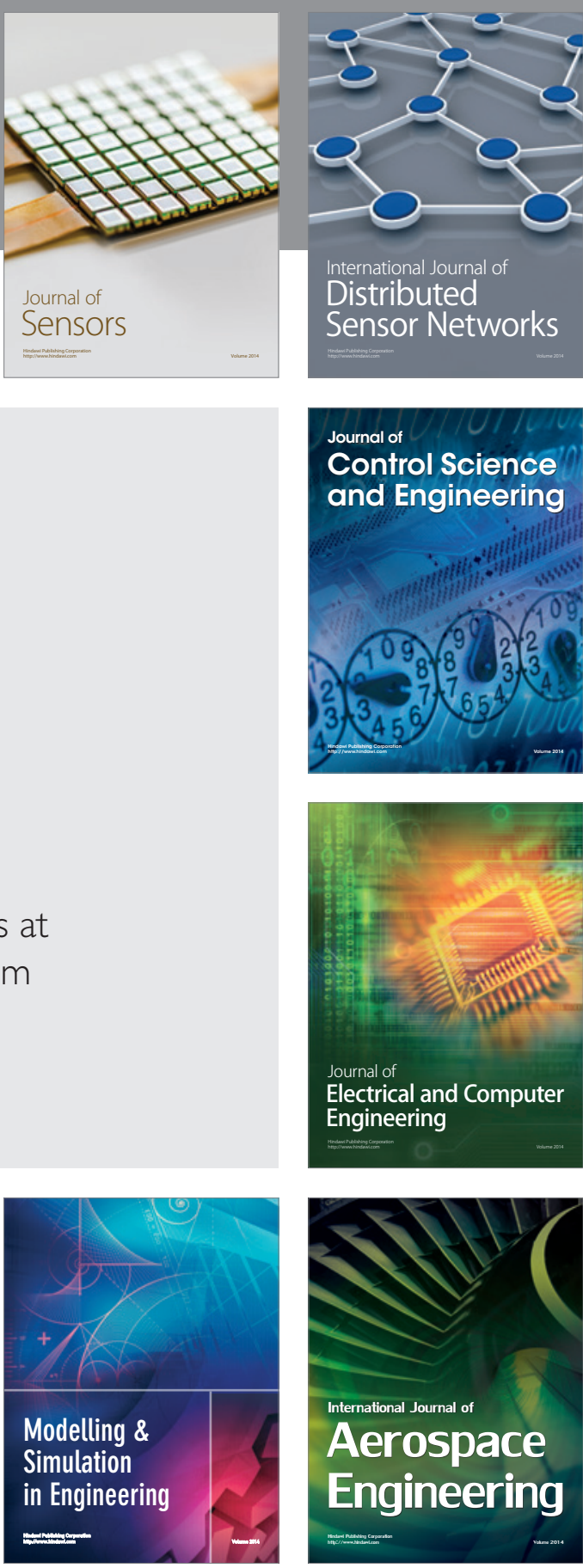

International Journal of

Distributed

Sensor Networks

$-$

Joumal of

Control Science

and Engineering
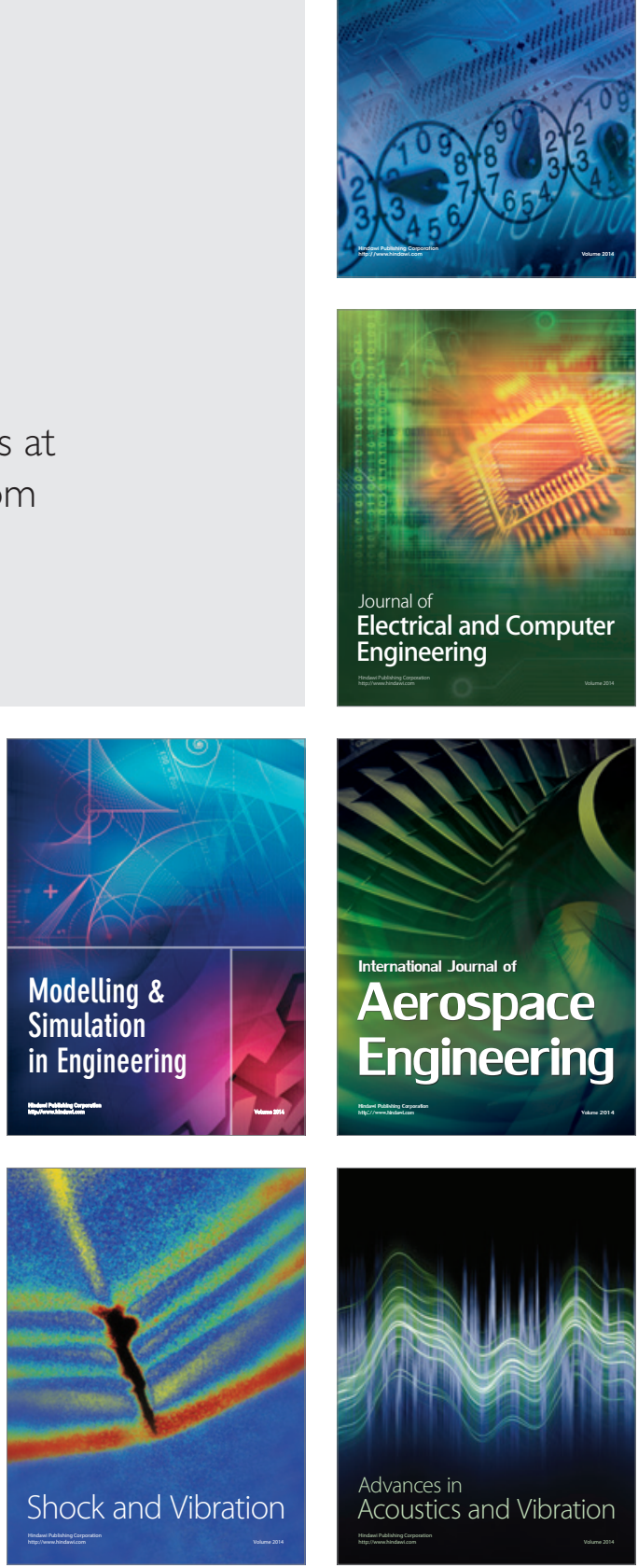